\title{
SISTEM INFORMASI MANAJEMEN PENELITIAN DAN PENGABDIAN MASYARAKAT LPPM IKIP MATARAM DALAM MENINGKATKAN MOTIVASI RISET DOSEN INTERNAL
}

\author{
Fitri Astutik $^{1}$, Muzakkir ${ }^{2}$ \\ Program Studi Teknologi Pendidikan \\ Fakultas Ilmu Pendidikan, IKIP Mataram \\ Fitriastutik@ikipmataram.ac.id,muzakkir@ikipmataram.ac.id
}

\begin{abstract}
Abstrak: Sistem informasi merupakan hal penting yang perlu dimiliki oleh lembaga, baik itu perusahaan-perusahaan maupun institusi pendidikan tinggi dalam mengolah data-data mereka. Seperti perancangan dalam penelitian ini yaitu pembuatan sistem infomasi manajemen pengelolaan data-data proposal penelitian dan pengabdian dosen IKIP Mataram. Karena selama ini penerimaan hibah penelitian dan pengabdian dosen IKIP Mataram masih dilakukan secara manual, untuk itu perlu dalam penelitian ini mengangkat judul melakukan pengambangan Sistem Informasi Manajemen Penelitian Dan Pengabdian Masyarkat Lppm Ikip Mataram Dalam Meningkatkan Motivasi Riset Dosen Internal, rumusan masalah dalam penelitian ini yaitu apakah sistem informasi manajemen penelitian dan pengabdian dapat meningkatkan motivasi riset dosen IKIP Mataram. Tujuannya adalah mempermudah proses pengusulan dan laporan penelitian dan pengabdian dosen IKIP Mataram. Penelitian ini menggunakan metode kualitatif, dengan pendekatan fenomenologi yang memfokuskan untuk memperoleh jawaban atas pertanyaan mengapa? dan bagaimana?. Dengan metode studi kasus (case study). Sedangkan untuk pengembangan sistem informasi manajemen menggunakan metode RAD (Rapid Application Development), mulai dari pengamatan (Observasi), kepustakaan (Libarary Research) dan laboratorium (Laboratorium Research). Hasil dari penelitian ini menunjukkan bahwa produk berupa website SIM LPPM sudah bisa manfaatkan karena dari hasil observasi dan pengamatan bahwa (1) sistem mampu melakukan valiadsi terhadap penamaan username untuk masuk ke dalam aplikasi, (2) sistem mampu melakukan validasi akan password yang dimasukkan tidak sesuai maka login tidak akan berhasil, (3) sistem mampu melakukan valiadsi terhadap penamaan kategori proposal, Judul, Abstrak dan upload File Proposal untuk menyimpan ke dalam aplikasi, (4) sistem mampu melakukan edit, update, tambahkan revisi dan unapproved saat akan melakukan perbaikan isi proposal kembali dan dosen-dosen bisa memanfaatkan produk tersebut sehingga ada peningkatan motivasi penelitian dan pengabdian kepada masyarakat bagi dosen IKIP Mataram.
\end{abstract}

Kata Kunci : Sistem Informasi Manajemen Penelitian, Motivasi Riset Dosen

\section{PENDAHULUAN}

Menyadari akan pentingnya keberadaan sistem informasi karena dapat memudahkan pengelolaan database pada sebuah institusi. Seperti hasil dari pengembangan sistem online yang sudah dilakukan oleh Sukadarmika Gede, dkk (2014), bahwa adanya sistem informasi pengelolaan proposal penelitian berbasis online akan sangat memudahkan pihak panitia di LPPM dalam memantau masing-masing jenis proposal baik dalam hal jumlah, progress kegiatan dan hasil penelitian akhir. Selain itu beberapa institusi sudah merancang pengelolaan sistem infromasi database berbasis website. 
Dengan adanya database hasil penelitian dan pengabdian kepada masyarakat dosen-dosen dapat mengakses dan menyunting dari manapun mereka berada tidak perlu datang ke kampus bahkan program yang sudah dikembangkan seperti di UNNES dapat dipakai sebagai publikasi produk yang dihasilkan oleh LP2M UNNES (Andrasto, 2013). Untuk itu perlu mengembangkan sistem infomasi manajemen pengelolaan data proposal penelitian dan pengabdian untuk dosen IKIP Mataram, karena selama ini sistem pengelolaan database penelitian dan pengabdian dosen IKIP Mataram masih manual dengan menggunakan aplikasi Microsoft Excel dan pengumpulan proposalnya berupa hardcopy, hal ini tidak efisien. Berdasarkan latar belakang yang telah diuraikan diatas maka peneliti mencoba mengembangkan sistem informasi berbasis website yang diberi judul "Sistem Informasi Manajemen Penelitian Dan Pengabdian Masyarkat Lppm Ikip Mataram Dalam Meningkatkan Motivasi Riset Dosen Internal".

Rumusan masalah dalam penelitian ini yaitu (1) Bagaimana merancang dan membangun sistem informasi manajemen penelitian dan pengabdian yang bisa diakses bagi LPPM dan Dosen IKIP Mataram melalui website, (2) Bagaimana produk hasil penelitian ini dapat mempermudah mengirim proposal, reviwe dan laporan akhir penelitian dan pengabdian masarakat ke LPPM. Batasan dalam penelitian ini hanya fokus dalam desian produk yaitu mengmbangakan sistem informasi berbasis website, dengan rincian (1) website ini hanya untuk pengolahan data penelitian dan pengabdian masyarakat hibah internal dosen tetap IKIP Mataram, (2) Sistem informasi ini akan terekam langsung di website IKIP Mataram, (3) Sistem informasi manajemen ini menggunakan bahasa pemrograman PHP MySQL. Adapun tujuan penelitian ini Mengembangkan sistem informasi manajemen penelitian dan pengabdian yang bisa diakses dimanapun, baik oleh LPPM dan Dosen IKIP Mataram (2) Dengan adanya produk ini agar mempermudah proses penerimaan proposal dan monitoring yang lakukan oleh LPPM IKIP Mataram. Dan salah satu manfaat penelitian ini, dosen bisa memliki akun masingmasing sehingga mempermudah mengusulkan proposal, mereviwe, mengirim laporan, begitu juga bagi LPPM, sedangkan manfaat bagi institusi IKIP Mataram, bisa mengontrol kinerja penelitian dan pengabdian para dosen tetapnya.

Sistem informasi manajemen (SIM) merupakan sistem yang digunakan untuk mengolah serta mengorganisasikan data dan informasi yang bermanfaat untuk mendukung pelaksanaan tugas atau kinerja dalam suatu organisasi. Kelebihan sistem baru (Sistem 
Informasi Menajemen) ini adalah input untuk pengajuan usulan surat tugas akan lebih mudah diorganisir serta dalam memperoleh informasi mengenai penelitian dan pengabdian baik perfakultas, perprogram studi dan persemester dengan cepat sehingga bila informasi tersebut dibutuhkan akan selalu tersedia dan penggunaan website database agar informasi dapat diakses melalui internet (Yanuardi dan Arief Jananto, 2005).

Sistem informasi manajemen menurut ahli (1) Menurut James A.F Stoner, sistem informasi manajemen merupakan metode formal yang menyediakan berbagai informasi yang tepat waktu, dapat dipercaya bagi pihak manajemen. Informasi ini digunakan untuk mendukung proses pengambilan keputusan dalam kegiatan perencanaan, pengawasan, dan fungsi operasi sebuah organisasi yang lebih efektif. (2) Menurut Bodnar dan Hopwood pada buku yang berjudul Accounting Information System menyatakan bahwa sistem informasi manajemen adalah kumpulan perangkat keras dan lunak yang kemudian dirancang untk mngubah data menjadi bentuk informasi yang berguna. (3) Menurut Jogiyanto Hartono (2000:700), pengertian sistem informasi manajemen adalah kumpulan dari interaksi sistem-sistem informasi yang bertanggung jawab mengumpulkan dan mengolah data untuk menyediakan informasi yang berguna untuk semua tingkat manajemen didalam kegiatan perencanaan dan pengendalian.

Rapid

Aplication

Development (RAD) Metode pengembangan sistem RAD adalah model proses pengembangan perangkat lunak yang bersifat incremental terutama untuk waktu pengerjaan yang pendek (Pressman, 2005:81). Model RAD lebih dikenal sebagai metodologi pengembangan perangkat lunak yang berfokus pada membangun aplikasi dalam waktu yang sangat singkat (Bastian Cafriyanto, dkk, 2016). RAD bisa menghasilkan suatu sistem dengan cepat karena sistem yang dikembangkan dapat memenuhi keinginana dari para pemakai sehingga dapat mengurangi waktu untuk pengembangan ulang setelah implementasi (Adikristanto, 2010). Pendekatan RAD melingkupi fasefase sebagai berikut (Kendall \& Kendall, 2002) yang melibakan penganalisis dan pengguna dalam tahapan penilaian, perancangan, dan penerapan. yaitu (1) Requirements Planning (Perencanaan Syaat-syarat) Fase ini, pada fase ini berorientasi menyelesaikan masalah-masalah organisasi untuk mencapai tujuannya. (2) RAD Design Workshop Fase ini merancang dan memperbaiki yang bisa digambarkan sebagai workshop. (3) Implementation Pada fase ini, penganalisis bekerja dengan para pengguna secara intens selama workshop dan merancang aspek- 
aspek bisnis dan nonteknis perusahaan atau organisasi. Setelah aspek-aspek ini disetujui dan sistemsistem dibangun dan disaring, sistemsistem baru atau bagian dari sistem diujicobakan dan kemudia diperkenalkan kepada oganisasi. Berikut ini gambaran fase-fase model RAD.

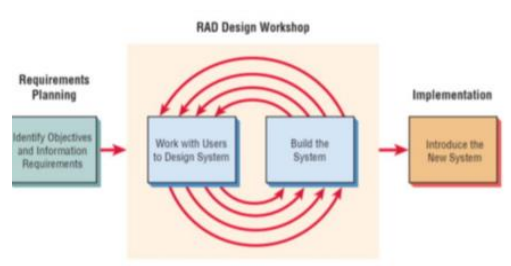

Gambar 1.1 Fase-Fase Rapid Aplication Development (RAD) (Sumber:

http://adikristanto.net/rapidapplication-development-rad/)

\section{METODE PENELITIAN}

Metode penelitian ini menggunakan pendekatan kualitatif, peneliti ini mencoba memahami secara mendalam fenomena yang diteliti dalam setting yang normal dan alami atau disebut pendekatan fenomenologi. Pendekatan fenomologi ini memfokuskan untuk memperoleh jawaban atas pertanyaan “mengapa? dan bagaimana?". Metode yang digunakan pada penelitian ini adalah studi kasus (case study). Sedangkan penelitian pengembangan sistem informasi manajemen di penelitian ini menggunakan metode RAD (Rapid Application Development). Gambar 2.1 berikut merupakan gambaran tahapan metode penelitian pengembangan sistem informasi RAD.

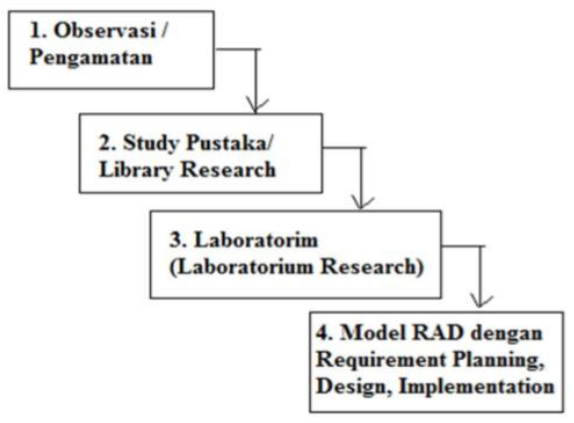

\section{Gambar 2.1 Tahapan Penelitian Pengambangan Model RAD}

Gambar di atas menjelaskan tahapan model RAD dengan penejelasan (1) Pengamatan (Observasi), dilakukan dengan mengamati sistem dan proses kerja yang sedang berjalan di LPPM IKIP Mataram sebagai objek penelitian. (2) Kepustakaan (Libarary Research) menggunakan buku-buku, hasil penelitian sebelumnya dan jurnal yang berhubungan dengan topik dan masalah penelitian ini. Laboratorium (Laboratorium Research), dilakukan di laboratorium komputer dalam hal ini data-data informasi yang terkumpul diproses, dan dibuat pemrogramannya guna menghasilkan sistem informasi sesuai dengan permasalahan yang ada di LPPM IKIP Mataram. Pada tahapan design, dilakukan analisis sesuai kebutuhan berdasarkan susunan pemanfaatan aplikasinya yang akan dibuat. Dimulai dengan Admin, kemudian login ke aplikasi selanjutnya perintah pengolahan 
database. Berikut gambar diagram rancangan interface penelitian ini.

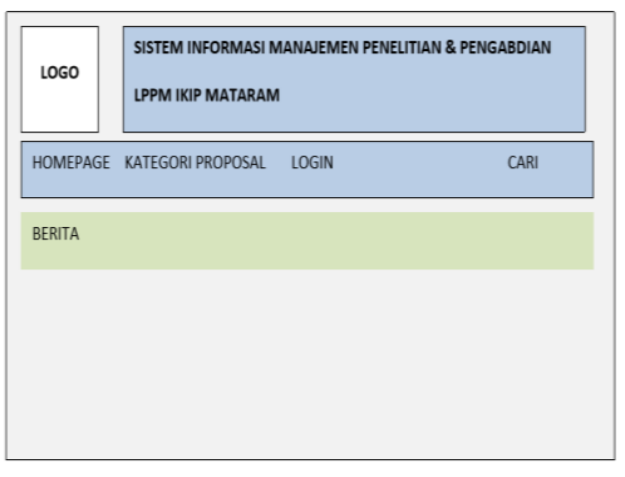

Gambar 2.2 Diagram Rancangan Interface Penelitian

Tahapan implementasi dapat dilihat dengan melakukan pengujian sistem informasi yang dibuat. Adapun implemtasi yang diharapkan pada interface dipenelitan ini seperti terlihat pada Gambar berikut.

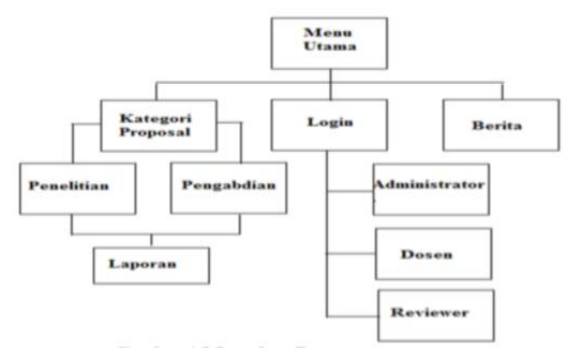

Gambar 2.3 Implementasi Interface Pada Sistem Informasi (Website)

\section{HASIL DAN PEMBAHASAN}

\section{Implementasi Sistem}

Pada sistem Login sebagai admin, Gambar 3.1 berikut ini merupakan tampilan dari hasil interface login sebagai Admin, dengan masuk ke link:

https://www.simlppm.com/admin/.

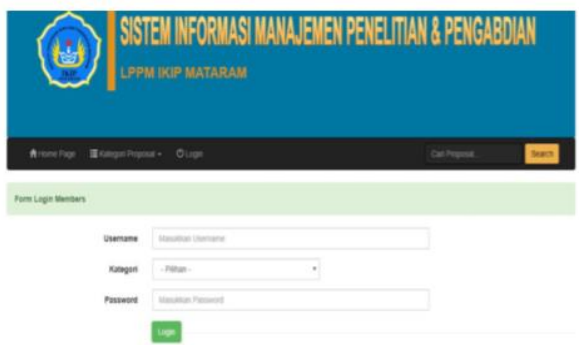

Gambar $\quad 3.1 \quad$ Login Sebagai Administrator Sistem

Pemakai sistem informasi yang masuk ke sistem sebagai Dosen dan Reviewer bisa masuk di link ini: https://www.simlppm.com/login.htm

\begin{tabular}{|c|c|c|c|}
\hline $\begin{array}{c}\text { Data } \\
\text { Masukan }\end{array}$ & Yang Diharapkan & $\begin{array}{c}\text { Hasil } \\
\text { Pengamatan }\end{array}$ & Kesimpulan \\
\hline Username & $\begin{array}{l}\text { Sistem mampu melakukan valiadsi } \\
\text { terhadap penamaan username untuk masuk } \\
\text { ke dalam aplikasi. Jika username yang } \\
\text { dimasukkan salah maka tidak aka masuk } \\
\text { ke menu sebagai user }\end{array}$ & $\begin{array}{l}\text { Notifikasi } \\
\text { username salah } \\
\text { pada sistem } \\
\text { muncul }\end{array}$ & OK \\
\hline Password & $\begin{array}{l}\text { Sistem mampu melakukan validasi akan } \\
\text { password yang dimasukkan tidak sesuai } \\
\text { maka login tidak akan berhasil. }\end{array}$ & $\begin{array}{l}\text { Notifikasi } \\
\text { kesalahan } \\
\text { password pada } \\
\text { sistem muncul }\end{array}$ & OK \\
\hline
\end{tabular}

\section{Gambar 3.2 Tampilan Login untuk Dosen dan Reviewer}

Gambar 3.2 Tampilan Login untuk Dosen dan Reviewer Pada Gambar 3.2 tersebut pengguna bisa Login sesuai dengan yang terdaftar didalam sistem tersebut, yaitu sebagai Dosen atau sebagai Reviewer. Hasil sistem informasi pada gambar diatas telah dilakukan pengujian sistem untuk pengujian login nya, dan diuraikan didalam Tabel 3.1 berikut ini. 
Berikut merupakan contoh tampilan interfase pilihan My Proposal yang sudah di submite

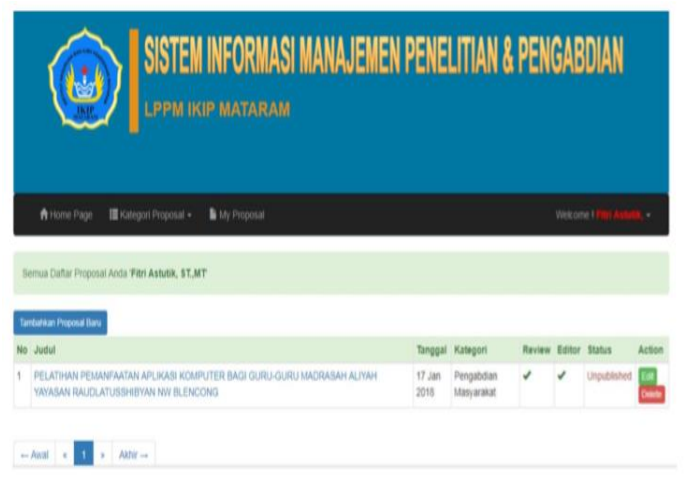

\section{Gambar 3.4 Tampilan Contoh Proposal Pada Sistem}

Berikut tampilan interface menggunakan Login sebagai Reviewer dapat diperlihatkan pada Gambar 3.5 berikut ini:

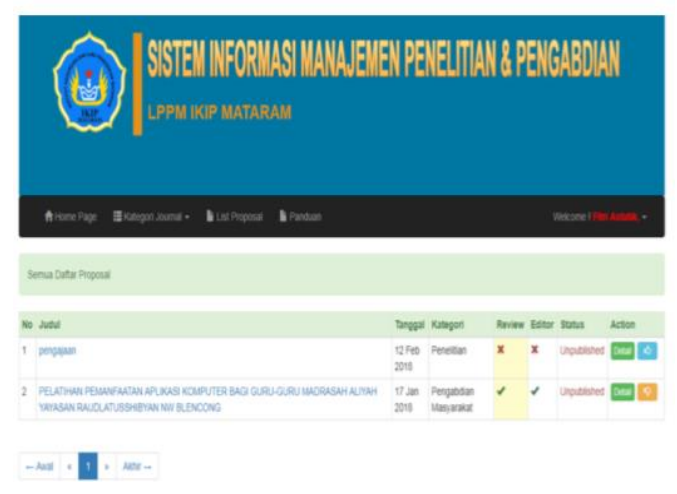

Gambar 3.5 Tampilan List Proposal di Akun salah satu Reviewer

\section{KESIMPULAN}

Berdasarkan hasil pengujian menggunakan metode Black Box Testing, aplikasi SIM LPPM yang telah dibuat tidak ditemukan permasalahan dari sistem. Sistem yang dibuat juga telah sesuai dengan perancangan dan desain awal. Setiap user yang mempunyai akses ke dalam sistem sudah memiliki hak akses berdasar dari tugas dan lingkup pekerjaannya masing-masing. Pengolahan database melalui sistem informasi managemen berbasis website lebih efektif bahkan memudahkan dalam proses penerimaan proposal, reviwe dan monitoring proposal dan laporan penelitian dan pengabdian kepada masyarakat bagi dosen IKIP Mataram.

\section{DAFTAR PUSTAKA}

Achmad Solichin, 2010. Pemrograman Web dengan PHP dan MySQL. Diakses di : achmatim.net/download/18/.

Anon Kuncoro Widigdo, 2003. Dasar Pemrograman PHP dan MySQL. Diakses di http://jatim.kemenag.go.id/file/ file/Umum/yrlg1395823105.pd f.

Andrasto, Tatyantoro. 2013.

Pengembangan Sistem

Database Hasil Penelitian Dan Pengabdian Kepada Masyarakat Dosen UNNES. Jurnal Teknik Elektro Vol. 5 No. 2 Juli - Desember 2013. https://journal.unnes.ac.id/nju/i 
ndex.php/jte/article/view/3556.

(Di akses 15/10/2019)

Fathul Wahid, 2004. Metodologi Penelitian Sistem Informasi: Sebuah Gambaran Umum. Media Informatika. 2 (1): 6981.

Heribertus Ary Styadi, Agung Nugroho, 2010. Kolaborasi Sistem Informasi Dan Sistem Pendukung Keputusan Untuk Menghasilkan Penilaian Sasaran Kerja Pegawai Bagi Dosen. Jurnal Unimus. Diakses di

http://jurnal.unimus.ac.id/index .php/psn12012010/article/view $/ 2299 / 2275$

Mursyidah, Hari Toha Hidayat, 2017.

Pengujian Sistem Informasi Akuntasi Biaya Operasional

Sekolah Dengan Black Box

Testing. Jurnal Infomedia.2 (2):

1-14.

Saipul Anwar, 2017. Sistem

Informasi Elektronik Kuliah

Kerja Nyata (E-KKN) Berbasis

Web Service pada Lembaga

Penelitian dan Pengabdian

Masyaakat (LP2M) Universitas

Islam Negeri Raden Fatah
Palembang. Intelektualita, 6 (2): 181188

Sukadarmika, Gede. Linawati1, Gusti M, ade Arya Sasmita, Nyoman Putra Sastra. 2014. Sistem Informasi Pengelolaan Proposal Penelitian Dan Pengabdian Masyarakat Secara ON-LINE. Vol. 13 No. 2 Juli - Desember 2014.

https://ojs.unud.ac.id/index.php /JTE/article/view/18859

(Di akses 15/10/2019)

Yanuardi. Arief Jananto. 2005. Rancang Bangun Sistem Informasi Penelitian dan Pengabdian kepada Masyarakat. Jurnal Teknologi Informasi DINAMIK Volume X, No. 2, Mei 2005 : 84-95 ISSN : 0854-9524. https://www.unisbank.ac.id/ojs /index.php/fti1/article/view/15 (Di akses 15/10/2019) 